\title{
Perencanaan Arsitektur Enterprise Menggunakan Togaf ADM Pada Dispora Kota Salatiga
}

\author{
Adimas Agil Pangestu ${ }^{1}$, Kristoko Dwi Hartomo ${ }^{*^{2}}$ \\ ${ }^{1,2}$ Universitas Kristen Satya Wacana; Jl. Diponegoro No. 52-60, Salatiga, Kec. Sidorejo, \\ Kota Salatiga, Jawa Tengah 50711, (0298) 321212 \\ ${ }^{3}$ Jurusan Sistem Informasi, FTI UKSW, Salatiga \\ e-mail: ${ }^{1} 682017106 @$ student.uksw.edu, ${ }^{2}$ kristoko@uksw.edu
}

\begin{abstract}
Abstrak
Dinas Kepemudaan dan Olahraga (DISPORA) Kota Salatiga merupakan salah satu organisasi pemerintah yang berfokus pada peningkatan prestasi olahraga dan potensi pemuda. Kesinambungan strategi bisnis dan TI adalah suatu proses yang selaras dan berkelanjutan. DISPORA sendiri saat ini belum sepenuhnya menerapkan sistem informasi yang saling terintegritas pada semua bidang yang ada. Perencanaan arsitektur enterprise dapat mengintegritaskan sistem saat ini dengan sistem yang akan datang. Metode yang digunakan adalah TOGAF ADM dengan cara melakukan wawancara dan observasi. TOGAF ADM adalah suatu metode yang terdiri dari langkah-langkah dalam perancangan arsitektur enterprise untuk perusahaan atau organisasi. Tahapan yang dilakukan hanya sampai fase Opportunities and Solutions. Hasil yang ditemukan dalam penelitian ini adalah perlunya kesinambungan antar bidang agar kegiatan proses bisnis berjalan sesuai dengan yang diharapkan. Hasil dari penelitian ini menghasilkan blueprint usulan SI/TI guna menjadi landasan strategi kegiatan proses bisnis Dinas Kepemudaan dan Olahraga Kota Salatiga.
\end{abstract}

Kata kunci- SI/TI, arsitektur enterprise, TOGAF ADM

\begin{abstract}
The Office of Youth and Sports (DISPORA) of Salatiga City is a government organization that focuses on increasing sports achievement and youth potential. Continuity of business and IT strategy is a harmonious and continuous process. DISPORA itself currently has not fully implemented an integrated information system in all existing fields. Enterprise architectural planning can integrate current systems with future systems. The method used is TOGAF ADM by conducting interviews and observations. TOGAF ADM is a method that consists of steps in designing an enterprise architecture for a company or organization. The stages carried out are only up to the Opportunities and Solutions phase. The results found in this study are the need for continuity between fields so that business process activities run as expected. The result of this study produced a blueprint for the proposed IS/IT to become the basis for a strategic business process activity of The Salatiga City Youth and Sports Service.
\end{abstract}

Keywords - IS/IT, architecture enterprise, TOGAF ADM

\section{PENDAHULUAN}

emakin berkembangnya teknologi informasi, banyak yang harus dipenuhi oleh sebuah organisasi. Tata kelola dalam organisasi yang baik hanya bisa diraih apabila data dan informasi diolah dengan baik melalui integrasi data dan informasi antar area fungsional organisasi maupun secara umum. Oleh karena itu perancangan dan pengembangan sistem 
informasi wajib seimbang dan tersinkronisasi dengan arah, tujuan serta kebutuhan organisasi tersebut.

Dinas Kepemudaan dan Olahraga Kota Salatiga adalah salah satu organisasi pemerintah yang berfokus pada peningkatan prestasi olahraga dan potensi pemuda Kota Salatiga. Dinas Kepemudaan dan Olahraga diharapkan bisa memberikan layanan keolahragaan dan kepemudaan dengan baik dan terintegras dengan semua sistem pelayanan yang ada.

Hal ini menyebabkan munculnya kebutuhan akan keselarasan sistem informasi antara bidang satu dengan bidang yang lain, sehingga perlu dibentuk tata kelola teknologi informasi. Tata kelola organisasi tersebut tidak bisa terlepas dari perancangan arsitektur enterprise. Salah satu tujuan dari penerapan arsitektur enterprise adalah terciptanya kesinambungan antara fungsi bisnis dengan teknologi informasi maupun sistem informasi dari organisasi.

Strategi bisnis dan TI adalah proses yang selaras dan berkesinambungan karena selalu didorong oleh perubahan dan perkembangan pasar. Selain itu, hal tersebut mempengaruhi perkembangan TI saat ini, yang semakin mempengaruhi strategi bisnis organisasi [1].

EAP adalah suatu metode yang berpedoman pada kebutuhan bisnis/organisasi untuk merencanakan arsitektur enterprise yang terfokus pada arsitektur data, arsitektur aplikasi serta arsitektur teknologi [2]. Model arsitektur enterprise dengan TOGAF ADM menciptakan kesinambungan antara bisnis dan teknologi informasi yang dibutuhkan organisasi [3].

Saat ini Dinas Kepemudaan dan Olahraga Kota Salatiga belum menggunakan teknologi informasi dan sistem informasi secara optimal dalam melaksanakan proses bisnisnya. Ini terlihat dari masih rendahnya sistem informasi yang digunakan dalam mendukung operasional Dinas. Permasalahan pada Dinas Kepemudaan dan Olahraga Kota Salatiga adalah adanya bidang yang masih menjalankan fungsinya secara manual dan belum menggunakan sistem.

Perencanaan arsitektur enterprise ini diharapkan dapat membantu Dinas Kepemudaan dan Olahraga Kota Salatiga meningkatkan kinerja pelaksanaan tugas pemerintahan dengan baik dari sisi operasional, pengawasan dan pembangunan dapat lebih mudah dan lebih efisien, serta bisa melayani masyarakat dengan baik.

\section{METODE PENELITIAN}

\subsection{Penelitian Terdahulu}

Terdapat peneliti terdahulu yaitu Aprilia Arum S, dan Augie David M, yang berjudul "Perencanaan Arsitektur Enterprise Menggunakan Togaf ADM (Architecture Development Method) Pada Dinas Kesehatan Kota Salatiga" menegaskan bahwa Dinas Kesehatan Kota Salatiga telah diidentifikasi melalui analisis value chain yang dapat menghasilkan dua aktivitas yaitu aktivitas utama dan aktivitas pendukung. Dari aktivitas utama dan pendukung tersebut, maka dapat dihasilkan portofolio usulan aplikasi guna mendukung fungsi bisnis untuk memperlancar pertukaran informasi antar fungsi bisnis. Pada proses arsitektur teknologi menghasilkan gambaran infrastruktur jaringan untuk dapat dijadikan usulan dalam pengembangan. Dalam tahapan opportunities and solution yaitu mengevaluasi, mengidentifikasi gambaran yang dibangun untuk pengembangan baru maupun menggunakan kembali sistem yang sudah ada. Menghasilkan tabel celah analisis sistem informasi dan teknologi informasi yang menggambarkan kondisi saat ini dan masa depan [4].

Peneliti Christian Yulianto R, Risqiati, dan Prastuti Sulistyorini yang berjudul "Penerapan Model The Open Group Architecture Framework (Togaf) Untuk Perancangan Arsitektur Enterprise (Studi Kasus : STMIK Widya Pratama Pekalongan) "Arsitektur sistem informasi yang didapatkan bisa digunakan oleh stakeholder STMIK Widya Pratama dalam merencanakan arsitektur sistem informasi guna mengelola perguruan tinggi sesuai dengan visi dan misi yang direncanakan [5]. 
Marini, Sarwindah, yang berjudul "Model Arsitektur Enterprise Menggunakan Enterprise Architecture Planning(EAP)" mengatakan bahwa sistem blueprint pada tahapan pengujian implementasi sebagai acuan dalam perancangan sistem aplikasi yang mampu mendukung proses bisnis dalam Perancangan Arsitektur Enterprise di Akademik, dan arsitektur data dan teknologi yang diperoleh pada penelitian ini yang saling terintergrasi. Dengan adanya rancangan kegiatan model bisnis value chain porter akan dapat mendukung semua kegiatan akademik. Arsitektur yang dikembangkan akan menentukan kegiatan akademik di masa depan [6].

\subsection{Landasan Teori}

\section{2.1 Arsitektur Enterprise}

Arsitektur Enterprise merupakan kumpulan dari proses bisnis, aplikasi, teknologi, dan data yang mendukung dalam strategi bisnis suatu organisasi. Arsitektur Enterprise merupakan suatu rencana pencatatan, cetak biru dari struktur, susunan, pengaturan, pengelompokan fungsional, antar muka, data, protokol, logika fungsional, integrasi, dan teknologi dari sumber IT dan diperlukan untuk mendukung fungsi bisnis dan misi organisasi [7].

Kegunaan utama dari arsitektur enterprise adalah untuk menginformasikan, mengontrol, dan membatasi keputusan bisnis, terutama saat berinvestasi dalam teknologi informasi (TI). Arsitektur enterprise juga bisa digunakan sebagai jalan untuk meningkatkan efisiensi TI pada saat inovasi bisnis dikembangkan organisasi. Suatu organisasi harus menggunakan metode yang dapat digunakan untuk mengimplementasikan pengembangan arsitektur enterprise [5].

\section{2.2 Togaf ADM}

TOGAF merupakan metode terperinci untuk membuat, mengelola, serta mengimplementasikan arsitektur enterprise dan sistem informasi yang disebut Architecture Development Method (ADM) [5]. TOGAF juga membantu mengurangi risiko dalam pengembangan arsitektur organisasi [8].

Architechture Development Method (ADM) dirancang untuk memenuhi kebutuhan bisnis dan teknologi informasi berskala enterprise. ADM adalah sebuah fitur yang memungkinkan organisasi mendefinisikan kebutuhan bisnis dan membangun arsitektur spesifik untuk memenuhi kebutuhan [9]. Kunci utama TOGAF adalah Architecture Development Method (ADM) yang digunakan untuk mengembangkan arsitektur enterprise yang dapat memenuhi kebutuhan bisnis [10].

TOGAF ADM menyediakan serangkaian proses literatif mulai dari menyusun arsitektur, transisi, hingga mengelola proses realisasi arsitektur. Berdasarkan pemodelan arsitektur TOGAF ADM, terdapat 6 tahapan yang diimplementasikan:

1. Tahap Preliminary

2. Architecture Vision

3. Business Architecture

4. Information System Architecture

5. Technology Architecture

6. Opportunities and Solutions

Setiap tahapan-tahapan yang terdapat pada TOGAF ADM menggunakan lingkaran terpusat yaitu requirement management dalam perancangan sebuah arsitektur enterprise yang berpedoman pada suatu konsep pemecahan masalah dari permasalahan organisasi [11]. 


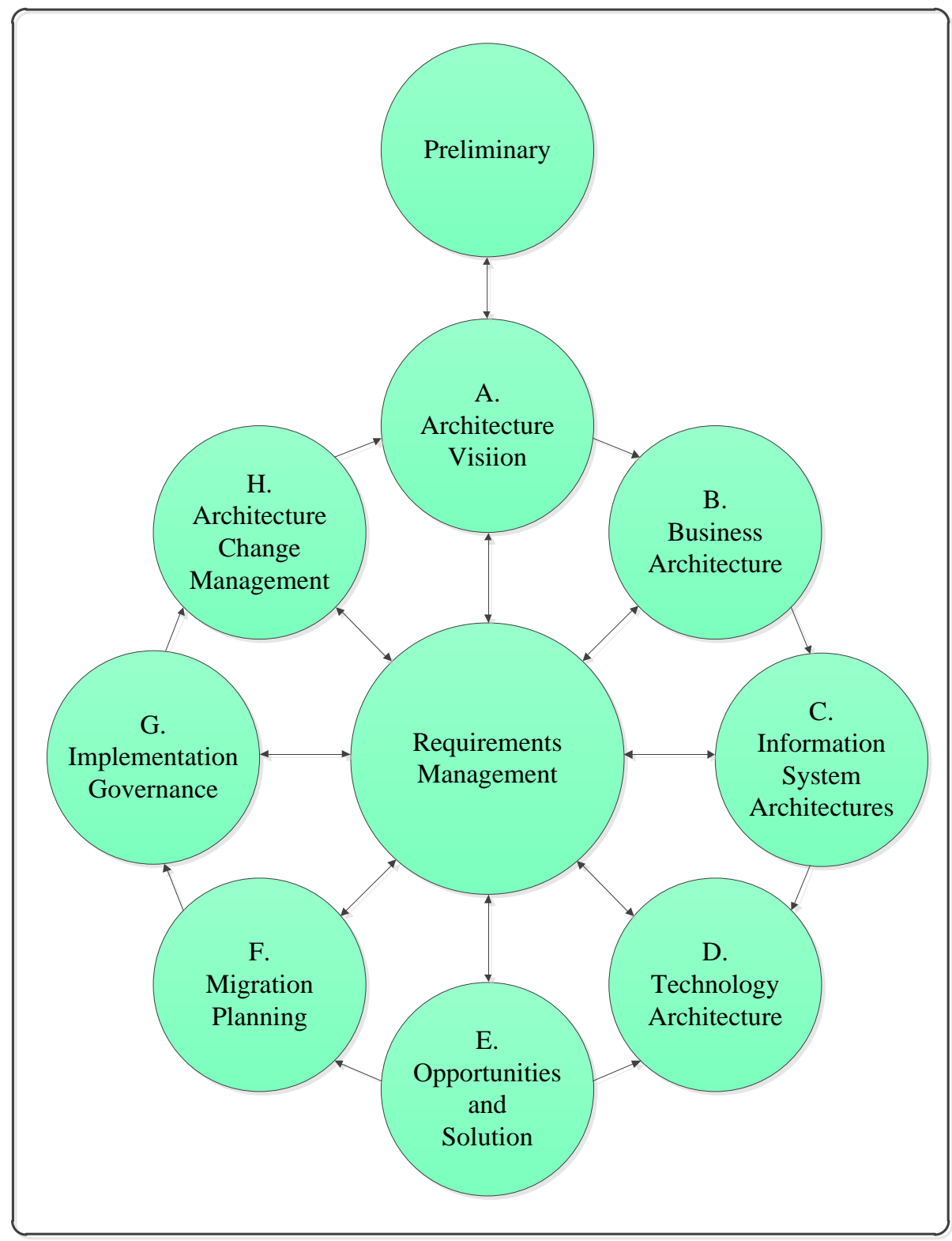

Gambar 1. Architecture Development Method

\subsection{Metodologi Penelitian}

Penelitian ini menggunakan metode kualitatif berdasarkan gambaran keadaan yang sebenarnya. Dengan menggunakan tahapan-tahapan standar yang ada pada TOGAF ADM. Langkah-langkah dalam penelitian:

1. Studi literatur mengenai arsitektur enterprise untuk memperoleh landasan teori arsitektur enterprise yang menggunakan metode TOGAF ADM.

2. Pengumpulan dan analisis data dilakukan pada bagian Sekretariat Dinas Kepemudaan dan Olahraga Kota Salatiga guna memperoleh informasi mengenai visi dan misi.

3. Untuk memperoleh informasi proses bisnis serta SI/TI dilakukan wawancara terhadap subbagian. Observasi yang dilakukan yaitu mengembangkan data yang didapatkan dan menganalisa data tersebut.

4. Penggunaan metode Togaf hanya sampai tahapan opportunities and solutions, dikarenakan tujuan dalam penelitian ini hanya fokus memberikan solusi dari permasalahan yang ada. 
5. Akhir dari penelitian ini bertujuan menghasilkan blueprint usulan SI/TI guna menjadi landasan strategi kegiatan proses bisnis Dinas Kepemudaan dan Olahraga Kota Salatiga.

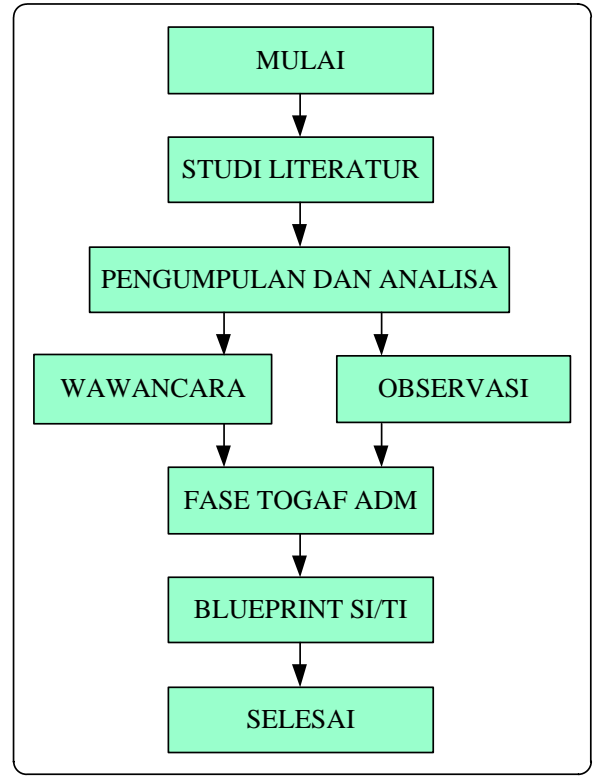

Gambar 2. Tahapan Penelitian

\section{HASIL DAN PEMBAHASAN}

\subsection{Fase Preliminary}

Dalam enterprise arsitektur organisasi pada Dinas Kepemudaan dan Olahraga Kota Salatiga memiliki aktivitas utama dan aktivitas pendukung. Aktivitas Utama dalam preliminary phase adalah Bidang Kepemudaan dan Kepramukaan, dan Bidang Keolahragaan. Sedangkan Aktivitas pendukung adalah Perencanaan dan Keuangan, Umum dan Kepegawaian.

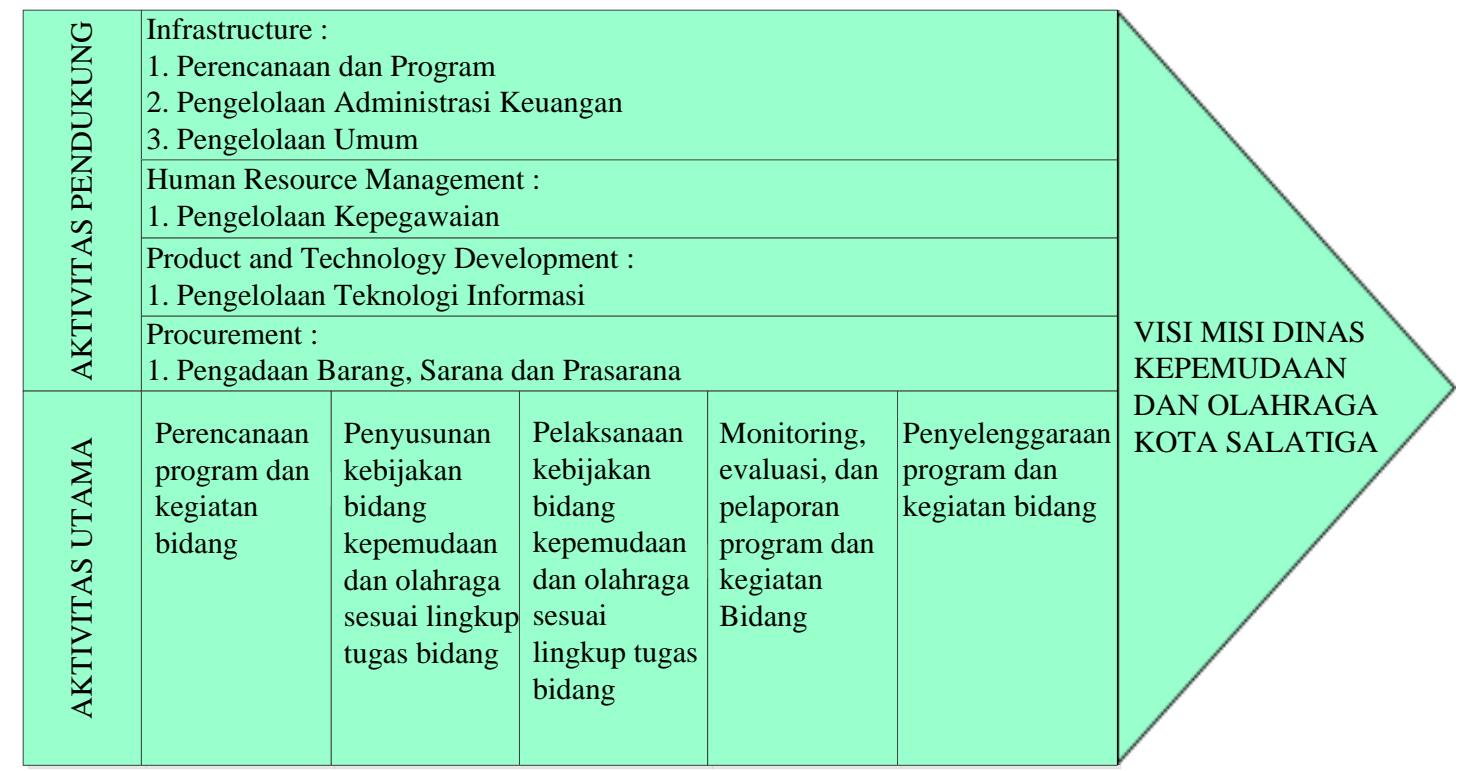

Gambar 3.Value Chain Dinas Kepemudaan dan Olahraga Kota Salatiga

Pangestu, et., al [Perencanaan Arsitektur Enterprise Menggunakan Togaf ADM pada Dispora Kota Salatiga] 


\subsection{Architecture Vision}

Dinas Kepemudaan dan Olahraga Kota Salatiga yang beralamat di Jl. LMU Adi Sucipto (GOR Pelajar Hati Beriman) Salatiga - Jawa Tengah - 50711. Visi dari Pemerintah Kota Salatiga "Salatiga HATI BERIMAN yang SMART". HATI BERIMAN merupakan singkatan dari sehat, tertib, bersih, indah dan aman. SMART merupakan singkatan dari sejahtera, mandiri, dan bermartabat". Tujuan organisasi memberikan informasi, memberikan perizinan dan melaksanakan pengawasan dan pengendalian teknis di bidang kepemudaan dan keolahragaan. Sasaran organisasi adalah meningkatkan potensi pemuda Kota Salatiga, meningkatkan prestasi olahraga di tingkat regional dan nasional, meningkatkan sarana prasarana pemuda dan olahraga, melakukan pembibitan pembinaan dan sosialisasi tentang olahraga. Kondisi arsitektur Dinas Kepemudaan dan Olahraga Kota Salatiga masih adanya bidang yang yang belum menerapkan sistem informasi, sehingga perlu adanya pengembangan sistem agar proses bisnis pada Dinas Kepemudaan dan Olahraga berjalan sesuai dengan yang diharapkan.

\subsection{Business Architecture}

Proses bisnis dalam Dinas Kepemudaan dan Olahraga Kota Salatiga memiliki beberapa stakeholder. Berikut adalah stakeholder yang berperan dalam proses bisnis utama dan pendukung dapat dilihat pada Tabel 1.

Tabel 1. Hubungan Stakeholder Dengan Aktivitas Organisasi

\begin{tabular}{|c|l|l|}
\hline \multicolumn{1}{|c|}{ Stakeholder } & DISPORA Kota Salatiga & Masyarakat \\
\hline $\begin{array}{c}\text { Utama } \\
\text { - } \begin{array}{l}\text { Bidang Kepemudaan } \\
\text { dan Kepramukaan }\end{array}\end{array}$ & $\begin{array}{l}\text { Kepala Dinas, Sekretariat, } \\
\text { Bidang Kepemudaan dan } \\
\text { Kepramukaan yang terdiri } \\
\text { dari Seksi Kepemudaan, Seksi } \\
\text { Kepramukaan; }\end{array}$ & $\begin{array}{l}\text { Masyarakat umum, Instansi } \\
\text { Pemerintah, Instansi Swasta, } \\
\text { Instansi Kepemudaan dan } \\
\text { Keolahragaan, Peneliti. }\end{array}$ \\
& $\begin{array}{l}\text { Bidang keolahragaan yang } \\
\text { terdiri dari seksi Pembibitan } \\
\text { dan Pembinaan Olahraga, }\end{array}$ & \\
& Seksi Pengembangan dan \\
& Pemasyarakatan Olahraga. & \\
Pendukung & Kepala Dinas, Sekretariat, \\
Perencanaan dan & Keuangan & Subbagian Perencanaan dan \\
Umum dan & Keuangan, Subbagian Umum \\
Kepegawaian & dan Kepegawaian. & \\
\hline
\end{tabular}

\subsection{Information Architecture}

Arsitektur aplikasi mendukung peran bisnis inti dan bisnis pendukung bisa didefinisikan berdasarkan kebutuhan informasi guna membantu pertukaran informasi antar peran bisnis. Berdasarkan kebutuhan, maka dirumuskan rekomendasi aplikasi untuk Dinas Kepemudaan dan Olahraga Kota Salatiga pada portofolio aplikasi yang dapat dilihat pada Tabel 2, kemudian dapat digambarkan seperti arsitektur bisnis pada Gambar 4. Aliran informasi antar sistem aplikasi bisa dilihat pada Gambar 5. 
Tabel 2. Portofolio Usulan Aplikasi

\begin{tabular}{|l|l|}
\hline \multicolumn{1}{|c|}{ Kode Aplikasi } & \multicolumn{1}{c|}{ Nama Aplikasi } \\
\hline SI 1.1 & Aplikasi Sistem Informasi Gelanggang Olahraga \\
\hline SI 2.1 & Aplikasi Sistem Informasi Kepemudaan \\
\hline SI 3.1 & Aplikasi Sistem Informasi Kinerja dan Realisasi Keuangan \\
\hline SI 3.2 & Aplikasi Sistem Informasi Perizinan Online \\
\hline SI 4.1 & Aplikasi Sistem Informasi Manajemen Barang \\
\hline SI 4.2 & Aplikasi Administrasi Surat \\
\hline SI 4.3 & Aplikasi Absensi \\
\hline
\end{tabular}

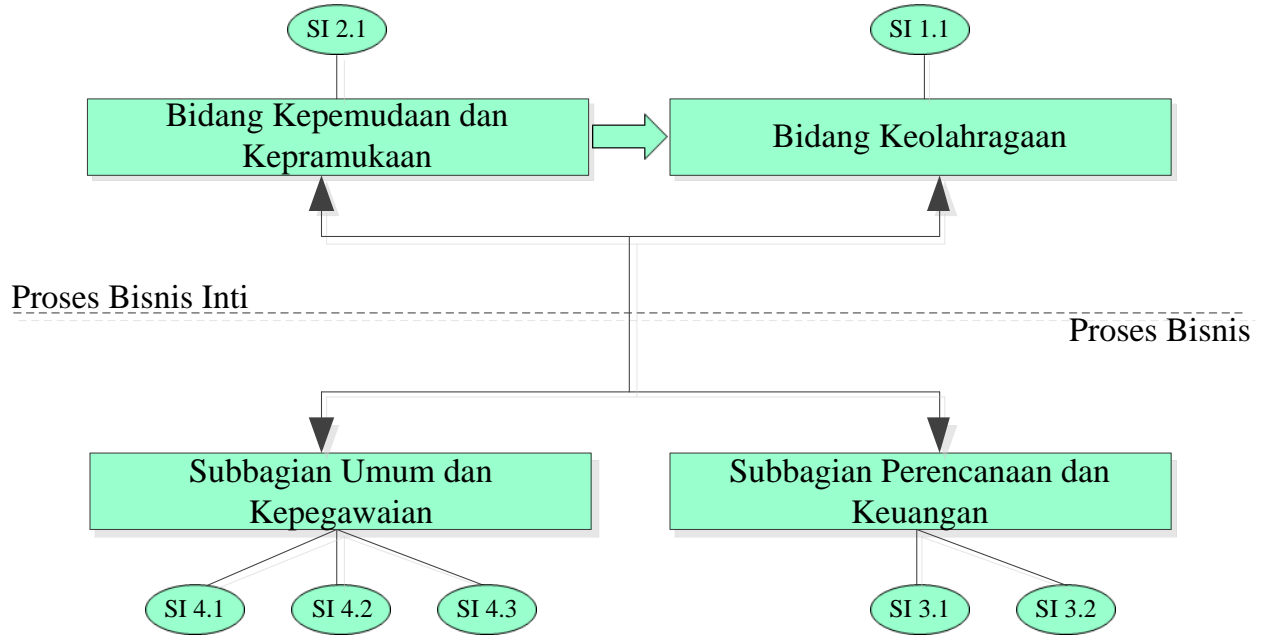

Gambar 4. Arsitektur Bisnis Dinas Kepemudaan dan Olahraga Kota Salatiga

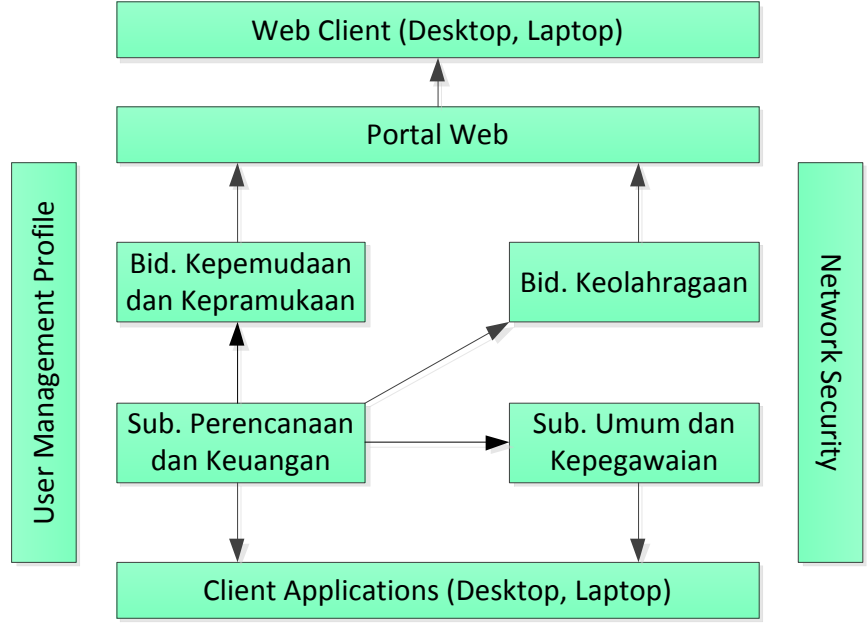

Gambar 5. Aliran Informasi Antar Sistem Aplikasi

\subsection{Technology Architecture}

Pada fase ini, peneliti melakukan analisa arsitektur teknologi yang sudah diterapkan, dilanjutkan membuat rencana untuk memperbaiki arsitektur teknologi yang ada agar sesuai dengan tujuan yang ingin dicapai. 
Tabel 3. Analisis Arsitektur TI Dinas Kepemudaan dan Olahraga Kota Salatiga

\begin{tabular}{|c|c|c|}
\hline No & Kondisi saat ini & Target \\
\hline 1 & $\begin{array}{l}\text { 30\% aktivitas bisnis yang dijalankan terkomputerisasi } \\
\text { - Pengelolaan data pada sekretariat }\end{array}$ & $\begin{array}{l}\text { 100\% seluruh aktivitas } \\
\text { terkomputerisasi }\end{array}$ \\
\hline \multicolumn{3}{|c|}{$\begin{array}{l}\text { Saran: } \\
\text { - Mulai dibangun sistem yang mengelola data pada masing-masing bidang. } \\
\text { - Absensi menggunakan face recognition untuk semua karyawan. } \\
\text { - Sering melakukan upgrade hardware. }\end{array}$} \\
\hline 2 & $\begin{array}{l}\text { 10\% menggunakan topologi jaringan } \\
\text { - Sekretariat }\end{array}$ & $\begin{array}{l}\text { 100\% kepentingan } \\
\text { konektivitas semua unit } \\
\text { menggunakan jaringan } \\
\text { topologi }\end{array}$ \\
\hline $\begin{array}{r}\text { Saran } \\
\bullet \\
\bullet \\
\bullet \\
\bullet \\
\bullet\end{array}$ & $\begin{array}{l}\text { Mulai menggunakan teknologi VLAN } \\
\text { Mulai menggunakan UPS } \\
\text { Menjalin kerjasama dengan platform penyedia jaringan } \\
\text { Maintenance jaringan secara berkala } \\
\text { Pengadaan hotspot di area Dinas Kepemudaan dan Ola } \\
\text { Pemasangan saluran telepon untuk komunikasi antar bi }\end{array}$ & $\begin{array}{l}\text { Iraga Kota Salatiga } \\
\text { dang (ruang kerja) }\end{array}$ \\
\hline
\end{tabular}

Berdasarkan hasil diatas, disarankan untuk merancang arsitektur enterprise Dinas Kepemudaan dan Olahraga Kota Salatiga berdasarkan waktu yaitu, rencana jangka pendek, menengah dan jangka panjang untuk mendukung proses bisnis Dinas Kepemudaan dan Olahraga Kota Salatiga.

Tabel 4. Rencana EAP Dinas Kepemudaan dan Olahraga Kota Salatiga

\begin{tabular}{|c|c|c|}
\hline Rencana Jangka Pendek & Rencana Jangka Menengah & Rencana Jangka Panjang \\
\hline 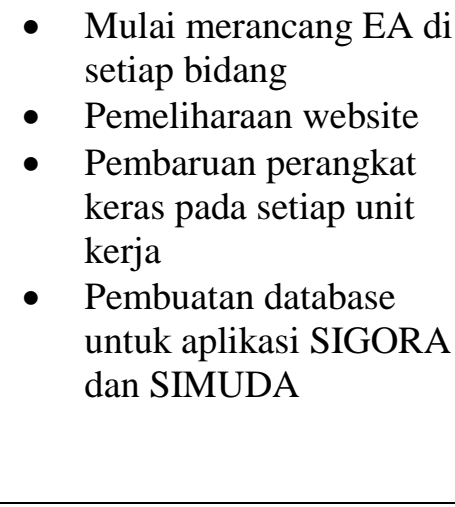 & $\begin{array}{ll}\text { - } & \text { Pembuatan SIGORA } \\
\text { - } & \text { Pembuatan SIMUDA } \\
& \text { Pembuatan SI Kinerja dan } \\
\text { - } & \text { Pembuatan KI Perizinan } \\
\text { - } & \text { Online } \\
\text { - } & \text { Pembuatan SIM Barang } \\
& \text { Absensi } \\
\text { - } & \text { Pembuatan Aplikasi } \\
& \text { Administrasi Surat } \\
\end{array}$ & $\begin{array}{ll}\text { - } & \text { Perekrutan SDM untuk } \\
\text { bidang IT } \\
\text { - } & \text { Semua unit } \\
\text { menggunakan sistem } \\
\text { informasi terintegrasi }\end{array}$ \\
\hline
\end{tabular}

\subsection{Opportunities and Solutions}

\section{6.1 Tabel GAP Sistem Informasi}

Gap sistem informasi merupakan sebuah tabel yang menggambarkan kondisi saat ini dengan masa depan. Dapat dilihat pada Tabel 3, aplikasi yang sudah ada perlu diupdate dan ada beberapa aplikasi yang harus ditambahkan (add) untuk membantu memenuhi kebutuhan kinerja proses bisnis di Dinas Kepemudaan dan Olahraga Kota Salatiga. 
Tabel 5. GAP Sistem Informasi

\begin{tabular}{|l|l|l|}
\hline \multicolumn{2}{|l|}{ Bidang Kepemudaan dan Kepramukaan } & Keterangan \\
\hline 1 & Aplikasi Sistem Informasi Kepemudaan & Add \\
\hline \multicolumn{2}{|l|}{ Bidang Keolahragaan } & Keterangan \\
\hline 1 & Aplikasi sistem Informasi Gelanggang Olahraga & Add \\
\hline \multicolumn{2}{|l|}{ Subbagian Umum dan Kepegawaian } & Keterangan \\
\hline 1 & Sistem Informasi Kepegawaian & Update \\
\hline 2 & Aplikasi e-Legal Drafting & Update \\
\hline 3 & Aplikasi Sistem Informasi Kinerja & Update \\
\hline 4 & Aplikasi Sistem Informasi Cuti Elektronik & Update \\
\hline 5 & Aplikasi Sistem Absensi & Add \\
\hline 6 & Aplikasi Sistem Informasi Manajemen Barang & Add \\
\hline 7 & Aplikasi Administrasi Surat & Add \\
\hline Subbagian Perencanaaan dan Keuangan & Keterangan \\
\hline 1 & Aplikasi Sistem Perencanaan Pembangunan Daerah & Update \\
\hline 2 & Aplikasi Sistem Informasi Manajemen Daerah & Update \\
\hline
\end{tabular}

\section{6.2 Tabel GAP Teknologi}

Gap yang memperlihatkan teknologi perangkat lunak dengan kebutuhan yang akan datang pada sisi teknologi perangkat lunak. Pada Tabel 6, bahwa terdapat teknologi perangkat lunak yaitu SO Windows 7,8,10; Microsoft Office 2010, 2013; untuk dipertahankan (retain). dan perangkat lunak Photoshop CC 2021 \& CorelDraw X7 untuk pembuatan sebuah desain; SQL Server 2005 dapat mendukung aplikasi arsitektur server/client, PHP untuk mendukung pembuatan website, Enterprise Firewall yang perlu ditambah (add) untuk menunjang kebutuhan proses bisnis di Dinas Kepemudaan dan Olahraga Kota Salatiga.

Tabel 6. GAP Teknologi

\begin{tabular}{|l|l|}
\hline \multicolumn{1}{|c|}{ Jenis } & \multicolumn{1}{|c|}{ Keterangan } \\
\hline Sistem Operasi Windows 7, 8,10 & Retain \\
\hline Microsoft Office 2010, 2013 & Retain \\
\hline Photoshop CC 2021 \& CorelDraw X7 & Add \\
\hline Enterprise Firewall & Add \\
\hline SQL Server 2012 & Add \\
\hline PHP & Add \\
\hline
\end{tabular}

\section{KESIMPULAN}

Berdasarkan penelitian yang dilakukan pada Dinas Kepemudaan dan Olahraga Kota Salatiga, telah diketahui funsgi bisnis dari analisa value chain. Analisa value chain tersebut menghasilkan 2 aktivitas yaitu aktivitas utama dan aktivitas pendukung. Dari aktivitas utama dan pendukung, dihasilkan usulan aplikasi yang diharapkan bisa meningkatkan proses bisnis yang ada. Pada fase arsitektur teknologi menghasilkan analisa teknologi saat ini dan target yang akan dicapai di masa yang akan datang. Tahapan pada opportunities dan solution berisi gap analisys yang menghasilkan tabel yang menggambarkan kondisi sistem informasi / teknologi informasi saat ini dan masa depan. Hasil penelitian ini, menghasilkan blueprint yang bisa berguna sebagai bahan acuan pengembangan sistem informasi / teknologi informasi pada Dinas Kepemudaan dan Olahraga Kota Salatiga. 


\section{SARAN}

Saran untuk peneliti selanjutnya adalah melanjutkan langkah-langkah yang diterapkan oleh TOGAF ADM meliputi Migration Planning, Implementation Governance, Architecture Change Management dan Requirements Management untuk meningkatkan kinerja proses bisnis bagi Dinas Kepemudaan dan Olahraga Kota Salatiga.

\section{DAFTAR PUSTAKA}

[1] R. E. Pariama. 2020, "Enterprise Arsitektur Planning (EAP) Untuk Universitas Pattimura Menggunakan TOGAF ADM," JATISI (Jurnal Tek. Inform. dan Sist. Informasi), Vol. 7, No. 2, pp. 277-288, doi: 10.35957/jatisi.v7i2.209.

[2] S. M. Putri, U. Hayati, and R. Dzulkarnaen. 2020, "Perancangan Arsitektur Electronic Medical Record (EMR) Menggunakan Metode Enterprise Architecture Planning (EAP) Arsitektur Enterprise," J. Inf. Technol., Vol. 2, No. 1, pp. 25-30.

[3] U. Faddillah, N. O. Syamsiah, and I. Purwandani. 2019, "Pemodelan Enterprise Arsitektur Sistem Informasi Penjualan Obat Menggunakan Kerangka TOGAF ADM," Indones. J. Softw. Eng., Vol. 5, No. 1, pp. 114-122, doi: 10.31294/ijse.v5i1.5871.

[4] A. A. Sari and A. D. Manuputty. 2018, "Perencanaan Arsitektur Enterprise Menggunakan Togaf Adm (Architecture Development Method) pada Dinas Kesehatan Kota Salatiga," Sesindo 2018, No. November.

[5] C. Y. Rusli, R. Risqiati, and P. Sulistyorini. 2018, "Penerapan Model The Open Group Architectural Framework (Togaf) Untuk Perancangan Arsitektur Enterprise (Studi Kasus Stmik Widya Pratama Pekalongan),” Pros. Semin. Nas. Int., Vol. 1, No. 1, pp. 1-8,

[6] M. Marini and S. Sarwindah, "Model Arsitektur Enterprise Menggunakan Enterprise Architecture Planning (Eap)," JSiI (Jurnal Sist. Informasi), Vol. 6, No. 2, p. 18, 2019, doi: 10.30656/jsii.v6i2.1556.

[7] Y. Mulyanto. 2017, "Perancangan Arsitektur Enterprise Untuk Mendukung Proses Bisnis Menggunakan Togaf Architecture Development Methode," J. TAMBORA, Vol. 2, No. 1, pp. 1-22, doi: 10.36761/jt.v2i1.151.

[8] D. A. Permatasari, A. Rachmadi, and W. Purnomo. 2019, "Pemodelan Arsitektur Bisnis pada Pelayanan Publik Polres Bojonegoro Dengan Pendekatan Enterprise Architecture," J. Pengemb. Teknol. Inf. dan Ilmu Komput., Vol. 3, No. 10, pp. 1005410063.

[9] A. D. M. Pada, R. Soedarso, E. Wati, and F. Devita. 2018, "Perencanaan Arsitektur Enterprise Menggunakan Metode Togaf," pp. 153-157.

[10] D. Irmayanti and B. Permana. 2018, "Perencanaan Arsitektur Enterprise Sistem Informasi Disnakersostrans Kabupaten Purwakarta Menggunakan TOGAF," J. Teknol. Rekayasa, Vol. 3, No. 1, p. 17, doi: 10.31544/jtera.v3.i1.2018.17-28. 
[11] F. Leni. 2016, "Perancangan Arsitektur Enterprise Sistem Informasi Dengan Menggunakan Togaf-Adm,” Algoritma, Vol. 13, No. April, pp. 443-450. 